\title{
Prospects for the Development of Human Resources in the Digital Economy Era
}

\author{
Natalia Kaufman ${ }^{1}$, Nailya Khadasevich ${ }^{1}$, Marina Glushchenko ${ }^{2}$, Svetlana \\ Zelentsova $^{1}$, Irina Sergeeva ${ }^{1}$, Marina Imamverdieva ${ }^{1}$ \\ ${ }^{1}$ Surgut State University, Russia \\ ${ }^{2}$ Omsk State Technical University, Russia \\ *Email: ntlru@gmail.com
}

\begin{abstract}
The article defines the role and place of high technologies at the current stage of social development, considers the principles of human resources development at the current stage, and identifies the reasons for changing the role of knowledge. The digital economy essence and the personnel requirements in the conditions of the digital transformation of all spheres of life are revealed. The human resources concept and its development conditions are reflected, HRprocesses in terms of digital transformation and staff expertise in the digital economy are listed, the analysis of changes in workplaces in the regions over the last 10 years is conducted. In connection with the identified factors, there is an increasing need to develop digital tools and digital skills to increase the competitiveness of the organisation and staff, since their use can guarantee the digital security of the business. Therefore, at the level of each member of society, there should be motivational aspects in improving life quality through self-improvement of their knowledge and skills level.
\end{abstract}

Keywords: Digital economy, Competitiveness, Digitalisation, Personnel, Competencies, Human resources.

\section{INTRODUCTION}

Socio-economic relations in Russia over the past decades have changed with the transformation of the world community, having a direct impact on the labour market and the demand for labour in it. Throughout the socialist system in our country, due to centralised management, the distribution of labour, production and everything else, the primary professions were directed to physical labour, mainly technical skills were developed in education, despite the emergence of new knowledge and skills. A significant part of the accumulated human capital was "non-market" could have economic value only in the specific context of a planned economy [1].

Since the first years of the 21st century, the digital economy, together with scientific and technological progress, complement each other, changing the idea of the labour force and the labour market. The introduction of automation and other new technologies transforms the structure of the labour market, transferring the vector of employers to the information competence of specialists who are able and ready to accept changes and improve their professional level with new relevant competencies.

\section{RESEARCH METHODOLOGY}

The research purpose is to generalise and assess the conditions for the development of the human resources potential of organisations in Russia, as well because of the development of the digital economy. Both theoretical and empirical methods of scientific knowledge were used in the study, allowing to systematise the existing methods and systems of indicators for the development of the competitiveness of human resources. Methods of logical, comparative, economic and statistical analysis and official statistical data were used. Research of the scientific community confirms the need for further study of opinions on the issue under study and identification of factors affecting the development of human resources. 


\section{STUDY RESULTS}

The digital economy affects not only information and communication links but also the qualification level and competence of personnel. High personnel potential forms modern and competitive subsystems of personnel management in organisations: personnel development and planning, recruitment and selection of personnel, adaptation, organisation and rationing of labour, motivation, stimulation, etc. [2].

Many scientists have considered the concept of human resources potential. Still, all definitions are similar and characterise the ability of different categories of personnel to put their knowledge and skills into action in the course of work at each designated stage and following the goals of the organisation. In the general sense, "potential" is an opportunity for development, and concerning the concept of "personnel", it is a labour resource for working in an organisation, i.e., a specialist in a particular position with his education, experience and skills.

Gorelova E.N. and her colleagues believe that human resources potential is closely interrelated with the moral qualities of personnel, psycho-physiological development, as well as with the creative component and intelligence [3].

The closest approach to the scientific and technical development of organisations is the opinion of M. A. Miller, who considers the possibility of employees' contribution to the work of the organisation of personal development in the direction of the company's strategic goals, their ability to participate in innovative activities as a human resource potential [4].

Balina T.N. speaks about the development of human resources, which is to ensure maximum compliance of the professional capabilities of the employee with the requirements that are imposed on the position he holds [5].

According to the authors, human resources depends on training, skills "hard skills" and "soft skills" and the quality of tasks both current and strategic. Thus, in the personnel management system, the personnel potential characterises the symbiosis of capabilities and abilities of personnel, aimed at achieving goals per the chosen strategy of the organisation.

For many decades in Russia, personnel were perceived by employers as a tool to achieve the goals of the organisation by performing traditional, standard work that does not require creativity and the desire for constant knowledge of new information. But, in the early 90s, Russia entered a new path of development - a market economy, since 2008, the market economy has received a "new wrapper" in the form of an innovative economy aimed at developing the appropriate infrastructure - technology parks, business incubators, science cities and other economic zones.

In 2016, the Digital Economy program was developed in Russia [6]. The main goal of the program is to create an ecosystem of the digital economy of the Russian Federation, in which digital data will be a crucial factor of production in all spheres of socio-economic activity [7].

The digital economy is the economy of innovative development, which is formed and developed through the effective introduction of new technologies. Digitalisation is the process of converting the entire information and social system into a digital format and transmitting it using various material media.

As per the program "Digital Economy of the Russian Federation", education and personnel are assigned to the basic digital economy development directions in Russia for the period up to 2024. Digitalisation is a new form of hyper-connected organisation and collective talent management that will change the role of the HR department.

The development of information technologies is also changing the labour market, as the digital economy needs specialists with a high level of digital competencies, ready to continually replenish and update their knowledge following the increasing role of knowledge in society. The Russian labour market has been significantly changed in the last decade.

Table 1 selectively presents data for 2009-2019 on changes in jobs in the regions of Russia [8].

Jobs created are positive values calculated for the working population aged 15-72 years. Reduced jobs are shown in the table with a minus.

According to the study results, from 2009 to 2019, in general, in Russia jobs number increased in 27 regions, but 56 subjects of the Russian federation - reduced. The leaders in job creation are Moscow and the Moscow region. This trend connected with many people who want to change their jobs due to low wages in their region or inability to find a job satisfying the individual.

In Russia, the goal is to increase the share of hightech and knowledge-intensive industries in the country's gross domestic product (GDP). In the development of the digital economy, the leading social risk in the labour market is the loss of jobs, which lose their relevance due to the lack of specialists with the necessary competencies.

The human resources potential of a modern specialist also depends not only on the employee him/herself but also on the ability of the region to provide the potential for self-realisation of personnel. Today, some regions are actively involved in high-tech sectors of the economy, for example, the Innopolis project in the Republic of 
Table 1. Changes in jobs in the regions over the past 10 years

\begin{tabular}{|l|c|c|}
\hline \multicolumn{1}{|c|}{ Subject of the Russian Federation } & $\begin{array}{c}\text { Number of jobs created over } \\
\text { the past 10 years (2009-2019), } \\
\text { thousand }\end{array}$ & $\begin{array}{c}\text { Changes in the number of jobs } \\
\text { over 10 years, in \% }\end{array}$ \\
\hline Moscow & 847,8 & 13,4 \\
\hline Saint-Petersburg & 258,6 & 9,4 \\
\hline Moscow region & 237,8 & 6,3 \\
\hline Krasnodar region & 158,9 & 6,3 \\
\hline Khanty-Mansijsk Autonomous District - Yugra & 62,1 & 7,5 \\
\hline Belgorod region & 60,3 & 8,2 \\
\hline Tyumen region & 33,1 & 5,0 \\
\hline Leningrad region & 26,3 & 2,9 \\
\hline Tomsk region & 21,6 & 4,4 \\
\hline Novosibirsk region & 6,9 & 0,5 \\
\hline The Republic Of Altai & 0,1 & 0,2 \\
\hline Yamalo-Nenets Autonomous District & $-2,1$ & $-0,7$ \\
\hline Chelyabinsk region & $-3,8$ & $-0,2$ \\
\hline Kamchatka region & $-7,2$ & $-4,1$ \\
\hline Magadan region & $-12,2$ & $-12,8$ \\
\hline Omsk region & $-20,7$ & $-2,1$ \\
\hline Ryazan region & $-39,2$ & $-7,2$ \\
\hline Kurgan region & $-62,1$ & $-15,0$ \\
\hline The Republic Of Komi & $-101,1$ & $-19,9$ \\
\hline Kemerovo region & $-114,8$ & $-8,5$ \\
\hline
\end{tabular}

Tatarstan, an example of a city of the future with the implementation of information technologies.

The share of high-tech and knowledge-intensive industries in Russia's GDP by year is shown in figure 1 .

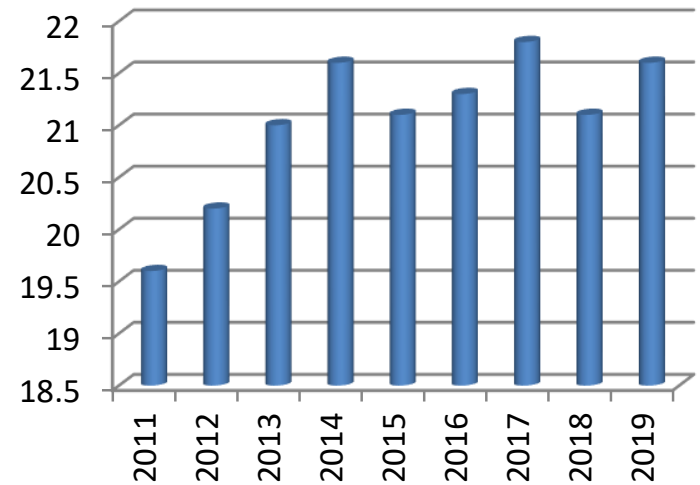

Figure 1 Share of high-tech and knowledge-intensive industries in GDP, \% of total.

As we can see, about $22 \%$ of GDP today contributes to the high-tech (hi-tech) sector. About thirty regions have achieved a positive increase in high-performance jobs by 2020 , of which 56.2 thousand jobs were created in ten regions - this is about $41.5 \%$ of the personnel potential of the high-tech sector of Russia. The top ten high-tech leaders are Moscow, Saint-Petersburg, Moscow region, Tatarstan, Sverdlovsk, Nizhny Novgorod, Samara and Chelyabinsk regions, Bashkortostan and Krasnodar region (fig.2).

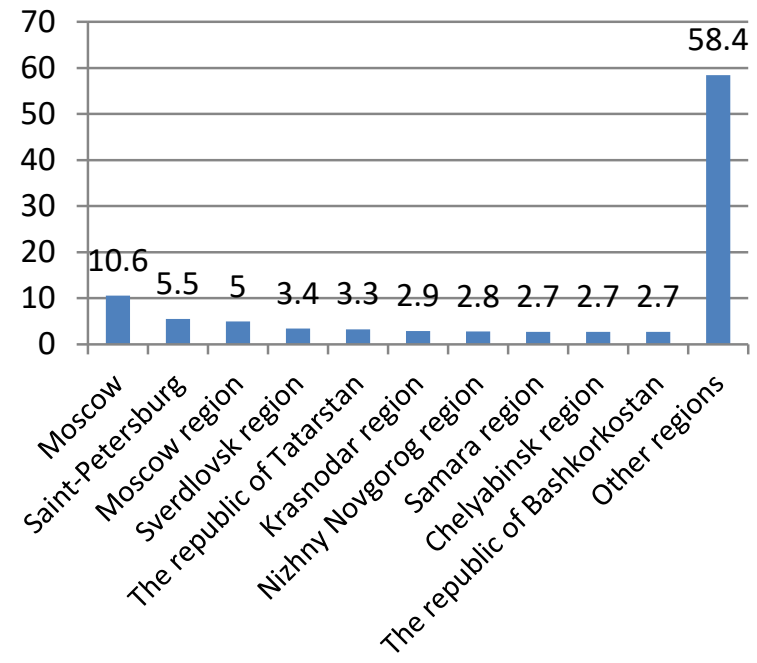

Figure 2 Regions-leaders in the concentration of employees in the high-tech sector in $2019, \%$.

In the regions shown in figure 2 , in addition to many high-tech organisations and knowledge-intensive services, favourable conditions have been created for attracting and increasing human capital. At the same time, a large amount of accumulated knowledge in the region also significantly increases the potential for creating a high-tech business.

The jobs reduction in the early 90s due to the closure of many factories in the city-forming cities is still evident in the regions. In the last decade, migration in the labour market has taken a stable position, and changing jobs in search of better conditions is a deliberate step for the 
working-age population. But to be competitive, it is necessary to keep up with scientific and technological progress, digitalisation, and continuously improve knowledge and skills, increasing the quality of your human resources.

Such changes are taking place not only in Russia but also all over the world. For example, in the united states, according to Carl Frey and Michael Osborne, about 47\% of the working population are employed in such jobs, which in one or two decades will be replaced by machines and artificial intelligence [9]. According to Kai-fu Li, known for the study of artificial intelligence, humanity is moving from the era of expert knowledge to the era of data [10].

Therefore, educational processes should always correlate with the labour market, training the population for the jobs created, considering the development of the necessary human resources. And the level of access to education should not be reduced but increased, then the possibility of self-determination in the economic environment will also increase.

\section{RESULTS DISCUSSION}

In the digital economy conditions, the approach to the system of training specialists is completely changing, since the availability of digital services and "smart" space allows you to live and work in more comfortable, but also completely new conditions. The advantage of "smart" space is that the interaction of the physical and digital environment allows you to work and relax more efficiently, changing social and economic factors. Today, technologies are present in everyday life, and the speed of their development is not a surprise for business.

The VUCA model can describe the unpredictability of many business processes:

- volatility;

- uncertainty;

- complexity;

- ambiguity.

In the HR sphere, this trend is also evident, since, in modern personnel management, all the principles of work were created according to predictable scenarios. In a transforming environment, they become ineffective.

In such conditions, the personnel management system, to be competitive, must adapt to the digital transformation and apply new technologies and processes. A change in the ratio of the leading HR processes is predicted, which can be divided into three degrees according to the degree of routine (fig. 3 ).

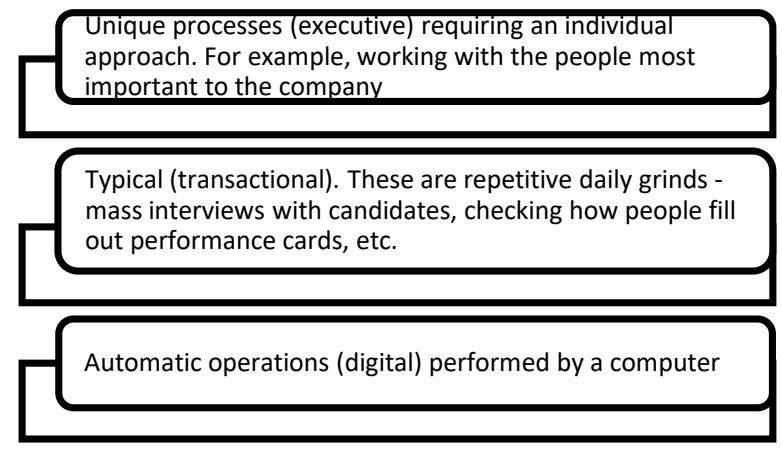

Figure 3 HR processes in a digital environment transformations.

According to McKinsey experts, about $30 \%$ of functions within the existing professions will be automated due to the technology's development. Also, approximately $14 \%$ of the world's labour force will be forced to change professions by 2030 [11].

Technology development according to experts of Boston Consulting Group (BCG), gradually creates a shortage of specialists who have the skills to use digital technologies, which means that the business community needs the following personnel policy: to invest in training personnel within their organisation or to engage them from the outside [12].

In such harsh conditions, large companies find forms of interaction with higher educational institutions. For example, the company Mail.Ru Group and Lomonosov Moscow State University are implementing a joint educational project in the form of the "Technosphere" program, aimed at obtaining students' knowledge in practice in the direction of mastering advanced Internet technologies. Students, studying in the project, develop programming skills in many areas while increasing the competitiveness of these students in the labour market [13].

Digital skills are now becoming an integral part of the professional skills of almost all professionals working in the industry, education, science, medicine, and many other fields of activity. We can refer to the competencies of personnel in the digital economy (fig. 4) [14]:

On the formation of new competencies of personnel background, the human resources potential of the organisation acquires an entirely new meaning. To the basic characteristics-specialised knowledge, experience, qualifications, and potential opportunities have added the potential of continuous personal development of the employee (self-expression, creative component); communication potential that allows you to use information flows effectively. Digital operations are taking the place of routine processes. Still, the increased requirements mostly relate to people, not to systems, and it will be difficult for $\mathrm{hr}$ managers to stay with the existing knowledge base. 


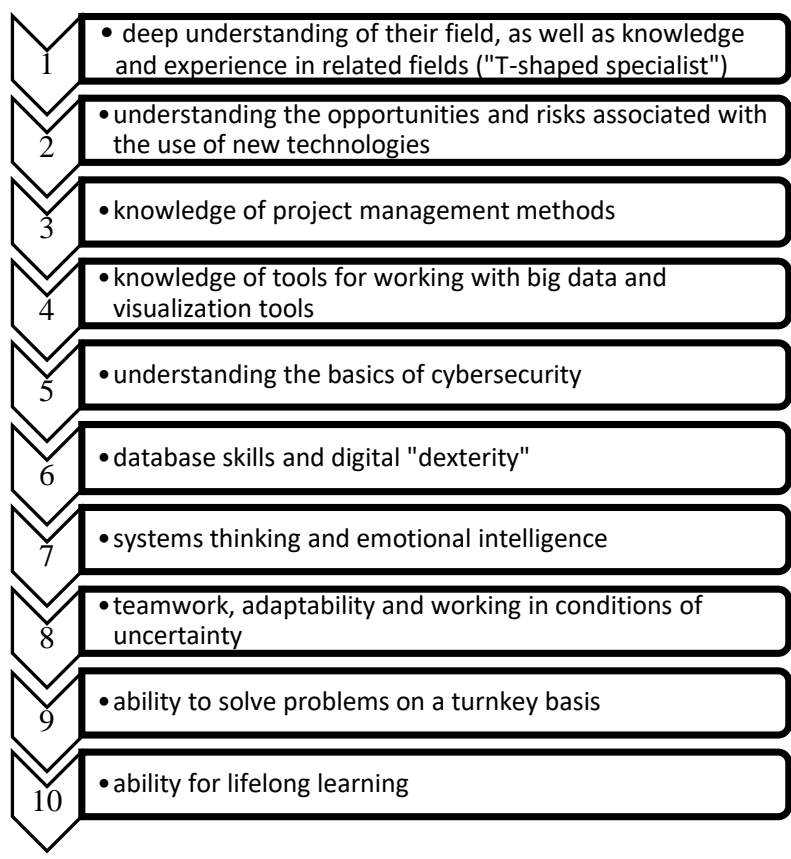

Figure 4 Staff competencies in the digital economy.

Thus, the use of digital technologies for employees is a way to release from daily grinding. Still, at the same time, it is a way to continually improve their skills, their intellectual level, the ability to think creatively, self-study and the ability to work with large amounts of data [15]. Digital learning is a new era of employee orientation [16]. For example, some areas of professions need to be receptive to the constant updating of their experience, be willing to experiment, have teamwork skills and literally run for scientific and technological progress [17]. Therefore, under these conditions, the digital transformation of cities has become relevant in Russia, which is based on several "megatrends" in the field of information technology, in particular: mobility, social communications, cloud technologies, big data and predictive analytics, machine learning and artificial intelligence, cybersecurity technologies, the "Internet of things" [18].

\section{CONCLUSIONS}

The modern economy peculiarity is manifested in the further development of the level of education, qualifications, the growth of jobs with the use of knowledge of modern digital technologies, and as a result, the reduction of employment in the industrial sector. Thus, the human resource potential in the digital economy depends on the desire of employees to develop and grow following new competencies, since the digital transformation of the economy provides fundamental transformations in all spheres of human life and activity.

Summing up the above, it should be emphasised that the high-tech sector, its development, depends on the availability of existing human resources, enough highly qualified specialists who possess the necessary set of knowledge and skills. The dynamic nature of the development of territories, the formation of the gross regional product, the definition of priorities of strategy and tactics make it necessary to create an adequate mechanism for managing human resources.

\section{REFERENCES}

[1] N.Yu. Kaufman, Problems of poverty in Russia: economic and social aspect, management 5 (2020) 36-45. DOI: https://doi.org/10.22394/2304-33692020-5-36-45

[2] M.I. Plutova, Prospects of personnel Management in the digital economy. Retrieved from: https://elibrary.ru/download/elibrary_37195149_19 517953.pdf

[3] E.N. Gorelova, M.A. Zotov, A.S. Ponikarova, Approaches to the formation of a management model for the innovative development of the personnel potential of the production system as a tool for achieving sustainability, Bulletin of the Kazan Technological University 19 (2012) 189-191.

[4] M.A. Miller, D.V. Shinkevich, Improving the quality of personnel in the service sector, Bulletin of OmSU. Series: Economics 1 (2013) 112-114.

[5] T.N. Balina, Acmeological model of development of the organisation's personnel potential, TMEI Bulletin 1(27) (2018) 59-66.

[6] The program "Digital Economy of the Russian Federation", Approved by order of the government of the Russian Federation No. 1632-p, July 28, $2017 . \quad$ Retrieved from: http://www.consultant.ru/document/cons_doc_LA $\underline{\mathrm{W} \_221756}$

[7] N.Yu. Kaufman, The transformation of knowledge management in the context of digital economy development, Creative Economy Vol. 12 Iss. 3 (2018) 261-270. DOI: https://doi.org/10.18334/ce.12.3.38922

[8] RIA Novosti (RIA Rating calculations based on Rosstat data). Retrieved from: https://riarating.ru

[9] C.V. Frey, M.A. Osborne, The Future of Employment: How Susceptible Are Jobs to Computerization? Technological Forecasting and Social Change Vol. 114 (2017) 254-280.

[10] Kai-Fu Li, The Superpowers of artificial intelligence, China, Silicon Valley and the new world order, translation from English by Nina Konstantinova, M.: Mann, Ivanov and Ferber, 2019, $240 \mathrm{p}$. 
[11] McKinsey Global Institute, A Future That Works: Automation, Employment and Productivity. Retrieved from: https://www.mckinsey.com

[12] G.Yu. Peshkova, A.Yu. Samarina, Digital economy and human resources: strategic interconnection and prospects, education and science Vol. 20 Iss. 10 (2018) 50-75. DOI: https://doi.org/10.17853/19945639- 2018-10-50-75

[13] About the project. Technoshere@Mail.ru, Retrieved from: https://sphere.mail.ru/pages/about/

[14] G.I. Abdrakhmanova, K.O. Vishnevsky, L.M. Gokhberg, What is the digital economy? Trends, competencies, measurement: report to $\mathrm{XX}$ Apr. International scientific conference on the problems of economic and social development, Moscow, 9-12 Apr. 2019, NRI Higher School of Economics, Moscow: Higher School of Economics Press, 2019, $82 \mathrm{p}$.

[15] D.V. Kruglov, The impact of digital technologies on the quality of human resources, Labour economic 5(4) (2018) 951-958. DOI: https://doi.org/10.18334/et.5.4.39631

[16] Josh Bersin, The Disruption of Digital Learning: Ten Things We Have Learned PUBLISHED MARCH 27, 2017, UPDATED AUGUST 14, 2019. Retrieved from: https://joshbersin.com/2017/03/the-disruptionofdigital-learning-ten-things-we-have-learned/

[17] V.E. Gimpelson, A.A. Zudina, R.I. Kapelyushnikov, Non-cognitive components of human capital: What the Russian Data say, Economic 11 (2020) 5-31. DOI: https://doi.org/10.32609/0042-8736-2020-11-5-31

[18] I. Sergeeva, E. Voronina, N. Khadasevich, N. Kaufman, S. Zelentsova, A. Litovchenko, "Smart" concept as a solution to the single-industry towns' development problems of the northern territorial entities in Russia. IOP Conference Series: Materials Science and Engineering 890(1) (2020) 012191. Retrieved from: https://iopscience.iop.org/article/10.1088/1757$\underline{899 X / 890 / 1 / 012191}$ DOI: https://doi.org/10.1088/1757-899X/890/1/012191 